\title{
Neoliberalismo y políticas públicas fragmentarias en el Centro-Oeste de Formosa, Nordeste Argentino
}

\author{
Neoliberalismo e políticas públicas fragmentadas no Centro-Oeste de Formosa, \\ Nordeste da Argentina
}

\author{
Neoliberalism and fragmentary public policies in the Center-West of Formosa, \\ Northeast Argentina
}

\author{
Ernesto Fabián Giuliano ${ }^{1}$
}

Recibido el 31/12/2019; revisado y aprobado el 03/11/2020; aceptado el 26/05/2020.

DOI: http://dx.doi.org/10.20435/inter.v21i4.2873

\begin{abstract}
Resumen: El presente trabajo tiene como objetivo analizar el proceso de plegamiento fragmentario de las políticas públicas productivistas, en el espacio territorial del Centro-Oeste de la provincia de Formosa (Nordeste Argentino), entre los años 1990 y 2015. La metodología que se sigue se apoya en distintas fuentes documentales, que dan cuenta de dicho proceso. A través de este análisis, se observa cómo la dinámica de plegamiento fragmentario de las políticas públicas productivistas estructura un patrón regulativo escalar neoliberal, generador de relaciones asimétricas de poder, en lo político, económico, y social. De modo que el territorio en estudio se transforma con la continuidad de desigualdades persistentes.
\end{abstract}

Palabras clave: Estado; neoliberalización; políticas públicas fragmentarias

Resumo: O objetivo deste trabalho é analisar o processo de dobramento fragmentário das políticas públicas produtivistas no espaço territorial do Centro-Oeste da província de Formosa (Nordeste Argentino), entre os anos 1990 e 2015. A metodologia seguida baseia-se em diferentes fontes documentais que explicam esse processo. Por meio desta análise, observa-se como a dinâmica de dobramento fragmentário das políticas públicas produtivistas estrutura um padrão regulatório escalar neoliberal, gerador de relações assimétricas de poder, nas esferas política, econômica e social. Assim, o território em estudo se transforma com a continuidade das desigualdades persistentes.

Palavras-chave: Estado; neoliberalização; políticas públicas fragmentadas.

\begin{abstract}
The objective of this work is to analyze the process of fragmentary folding of the productivist public policies in the territorial space of the Center-West of the province of Formosa (Northeast Argentina), between the years 1990 and 2015. The methodology that is followed is based on different documentary sources that account for this process. Through this analysis, it is observed how the dynamics of fragmentary folding of the productivist public policies structure a neoliberal scalar regulatory pattern, generator of asymmetrical relations of power, in the political, economic, and social. Thus, the territory under study is transformed with the continuity of persistent inequalities.
\end{abstract}

Keywords: State; neoliberalization; fragmentary public policies.

\section{INTRODUCCIÓN}

El siguiente trabajo transita durante los procesos económicos de consolidación de las políticas públicas neoliberales en la Argentina en la década del 1990; las que luego, en los primeros años del siglo XXI, van a mostrarse como nuevas formas de intervención estatal que intentan dar respuestas diferenciadas de aquellas políticas, pero, sin embargo, no implicaron su abandono radicalizado, sino su continuidad y proliferación abigarrada en la práctica a través de las ideas que estructuran la plataforma del pensamiento único localista (BRANDÃO, 2007).

Pensamiento que vectoriza los dispositivos de políticas productivistas fragmentarias asimiladas de manera acrítica por los policymaker que van instalando con esa lógica, nuevas formas de mercantilización y de articulación, con eje estratégico del desarrollo en las regiones

\footnotetext{
${ }^{1}$ Universidad Nacional de Formosa, Formosa, Argentina.
} 
y/o localidades y sus vínculos con la globalización, desplazando al Estado Nacional como núcleo de la acumulación.

En tal sentido, las acciones de la élite política y dirigencial que comanda el Estado en la provincia de Formosa - Nordeste Argentino -, ha trazado su propio sendero del proceso de neoliberalización. Al respecto, se propone observar estas acciones entre los años 1990 y el 2015 para el caso territorial del Centro-Oeste formoseño. Espacio donde se configuraron hacia mediados de los años 1990, las primeras experiencias que buscan mostrarse como superadoras del proceso neoliberal de aquella década que había profundizado las condiciones de deterioro social, económico y políticas, profundizando la condición de provincia integrante de la periferia rezagada de la Argentina (VACA; CAO, 2004).

En este contexto, el trabajo sigue la hipótesis que durante el período analítico las políticas públicas que se impusieron durante las reformas estructurales implantadas por el Consenso de Washington (CW), no lograron desterrarse de manera radicalizada; estas se reconfiguran en un complejo proceso de re-escalamiento del Estado y territorialización en las que se pliegan de manera abigarrada políticas públicas productivistas fragmentarias, mediadas con las fracciones del capital que operan en el Centro-Oeste de Formosa. Ese proceso dinamiza el corpus de un patrón regulativo escalar productivista, institucional y de infraestructuras que combina de manera complementaria las ideas de la plataforma única localista, como estrategias de promoción al desarrollo. Esas acciones desplegadas, siguen una lógica fragmentaria a la hora de implicar en el territorio, las que generan nuevas formas de mercantilización, vehiculizan la continuidad y reelaboración al proceso neoliberal y sus consecuentes desigualdades persistentes.

Los elementos empíricos que apoyan este estudio intentan mostrar esos cambios, continuidades y persistencia en el territorio analizado. Se sigue para ello, una metodología de tipo cualitativa que se combina con algunos elementos cuantitativos. El estudio utiliza distintas fuentes como: documentos y datos estadísticos de los organismos oficiales provinciales y nacionales, normas legales, documentos de organismos supranacionales, además de medios periodísticos (diarios de la ciudad de Formosa y nacionales).

Así en la primera parte se revisa la mutación del capitalismo y en ella, el proceso de cambio funcional y espacial del Estado, poniendo foco en el espacio territorial del Centro-Oeste de Formosa. En la segunda parte, se intenta dar cuenta sobre el proceso de plegamiento de las políticas públicas fragmentarias y las lógicas de intereses vinculados a la ganadería y los agronegocios, que usufructúan estas políticas explotando el territorio con perfil productivo extractivista, en tanto las poblaciones locales son llevadas por la acción conjunta de los actores globales dominantes y el Estado, a las ideas del pensamiento único localista a través de las experiencias del Bosque Modelo Formoseño y luego por los Planes de Desarrollo Local, instalando el ideario de alcanzar el desarrollo en espacios rurales donde la degradación ambiental y las desigualdades sociales persisten. Finalmente, las conclusiones procuran articular los elementos observados en función al marco conceptual y la hipótesis planteada.

\section{MUTACIONES DEL CAPITALISMO Y LOS CAMBIOS EN LA ESTATALIDAD EN EL CASO FORMOSEÑO}

La emergencia del arquetipo, o, como llama LIPIETZ (1994, p. 18), modelo de desarrollo posfordista, ha modificado la organización territorial de las formas de acumulación y del modo de regulación que relativizan el ámbito nacional y jerarquizan el global-local o regional. Para 
ello fue adoptando patrones flexibles, dinámicos, en ambientes de proximidad ${ }^{2}$, en redes históricamente heterogéneos. Todo ello, necesitó de un núcleo de fundamentos teóricos que luego serán institucionalizados a través de un camino complejo y de participación de distintas voces. En tal sentido, ese camino se inició en los países desarrollados con el tránsito desde los "distritos industriales" ${ }^{3}$, al enfoque evolucionista-institucionalista ${ }^{4}$ con los "milieux innovateurs" ${ }^{5}$ y su evolución a los "sistemas regionales de innovación" con Cooke (1992, p. 365), para converger a la configuración de "cluster" propuesta por Porter (1998, p. 78). De ese proceso complejo y diverso de voces, como bien fundamentan Fernández, Amín y Vigil (2008, p. 14) emergieron las bases teóricas que se adoptaron y replicaron en el campo de las políticas públicas de manera "acrítica" durante las últimas dos décadas en los países centrales y en los de América Latina, de la cual, la Argentina y Formosa no quedaron exentas en comulgar con esas bases el ascenso de los espacios gobal-local o regionales, como los núcleos estratégicos y desencadenantes de procesos de industrialización y desarrollo.

Esa emergente configuración, como se podrá apreciar en esta parte del trabajo, representa una reelaboración del proyecto neoliberal que introduce en la práctica, una lógica de co-producción de políticas con los actores regionales publico-privados, que imponen una extensión de los procesos de mercantilización, a través de una implicación estatal que facilita un renovado y más complejo proceso de desarticulación fragmentante al momento de accionar la dinámica regional.

Veamos, durante el súmmum del neoliberalismo en los años 1990 la Argentina profundizó el proceso de ajuste y de reformas estructurales delineadas por el Consenso de Washington, implicando: la reducción el Estado y sus atribuciones reguladoras, privatización de empresas públicas y bancos provinciales; la descentralización de funciones (educación y salud entre otros); la desregulación de todos los mercados, la apertura y el endeudamiento externo.

Esto es, se redefinieron los modos de relación y articulación del Estado con la sociedad civil, las modalidades (y objetivos) de intervención, sus formas organizativas, y se modificó el modelo de centralidad estatal ${ }^{6}$ y las estrategias de desarrollo que implicaron para esta década, la desaparición total de la industrialización basadas en la sustitución de importaciones (FERNÁNDEZ; GARCÍA PUENTE, 2010). De este modo, se dio lugar a una drástica modificación de la presencia del Estado en la dinámica de acumulación nacional, que se tradujo en los hechos, como señalan Rofman y Romero (1997, p. 253), en el paso de un Estado de Bienestar a un Estado Subsidiario.

Al calor y dominio creciente de las reformas neoliberales de retracción del Estado, como se adelantó al inicio de esta primera parte, comenzó a desarrollarse un conjunto de contribuciones

\footnotetext{
${ }^{2}$ Amin (1998, p. 77) explica que, en la visión institucionalista, la proximidad comprende los parámetros sociales e institucionales para la acción económica tales como: El poder de las lógicas y tradiciones de comportamientos locales; las propiedades de las redes de contacto cara a cara; la calidad de las instituciones locales, las normas sociales y las convenciones.

3 La definición original de distrito industrial se debe a Alfred Marshall en 1920, y ha sido rescatada y actualizada por Becattini (1992, p. 40) quien lo define como: "una entidad socioterritorial caracterizada por la presencia activa tanto de una comunidad de personas como de una población de empresas en un espacio geográfico e históricamente dado".

${ }^{4}$ Ambos cuerpos de pensamiento, expresa Amin (1998, p. 71), destacan la idea de que la vida económica es un proceso instituido y una actividad socialmente enraizada y, por lo tanto, su evolución está sujeta a un contexto específico y una trayectoria histórica.

5 Benko y Lipietz (1995, p. 7) señalan que los medios innovadores o milieux innovateurs fueron desarrollados pioneramente por el equipo europeo franco-italiano de GREMI (Grupo de Investigación Europeo sobre los Medios Innovadores - Asociación Phillippe Aydalot).

${ }^{6}$ También denominado matriz estadocéntrica y en el cual el Estado se constituyó como actor político, árbitro y, al mismo tiempo, arena de disputas por la distribución del ingreso y los conflictos sociales (CAVAROZZI, 2004 citado en FERNÁNDEZ; GARCÍA PUENTES, 2010).
} 
académicas originado en los países centrales. Estas contribuciones, se agruparon en una plataforma que Fernández, Amin, Vigil (2008, p. 12), denominan la Nueva Ortodoxia Regional (NOR) concordantes a las idas de Carlos Brandão.

Hacia mediado de los años 1990, esta perspectiva fue penetrando en los países periféricos y se propagó de manera acrítica la lectura neoliberal del desarrollo capitalista, institucionalizándose de la mano de intelectuales, e instituciones destacadas del mundo académico y supranacional de nivel regional, constituyéndose la NOR en una plataforma común.

Durante el transcurso de este período caracterizado por profundos cambios, Formosa estará signado por tres rasgos institucionales fundamentales: 1) las modificaciones sucesivas en dos oportunidades de la Carta Magna de la provincia; 2) la continuidad hegemónica del partidoEstado en la dirección política y administrativa del Estado y 3) a partir de los dos primeros, la implementación dominante del modelo formoseño para el desarrollo provincial (MFDP).

Esos rasgos comienzan a vislumbrarse cuando los marcos legales e institucionales de Formosa se transforman en 1991 con la primera reforma Constitucional, durante la gestión del Gobernador Vicente Bienvenido Joga que le permitirá su reelección (Art. 129 de la Constitución Provincial de 1991) repitiendo la fórmula para el cargo de Vicegobernador con Gildo Insfrán. Dicha reforma constitucional, consagrará nuevos institutos y derechos civiles7, adelantándose a los que se incluyeron en la Constitución Nacional, reformada en el año 1994.

Pero a su vez, es el comienzo de un poder hegemónico que tendrá su continuidad con la elección de Gildo Insfrán (1995-1999) y la cristalización del ideario redactado en el preámbulo de la Constitución de 1991: "[...] plasmar el modelo formoseño para un proyecto provincial [...]". Donde el grupo dominante, que encarnará política y económicamente ese proceso al que denominamos partido-Estado8, se constituirá desde entonces, en un factor determinante, para el asentamiento de espacios de acumulación, vinculados a la explotación de los recursos naturales.

Pese a que la Constitución provincial sólo permitía una reelección (Art. 1299 de la Constitución Provincial de 1991) el Superior Tribunal de Justicia, plasmará la interpretación de dicho artículo en la decisión de habilitarlo a Gildo Insfrán, para que participara en las elecciones de dicho año, que lo consagrará nuevamente Gobernador para el período 1999-2003.

En el año 2001, el Poder Ejecutivo Provincial (PEP) avanzará sobre el Poder Judicial, aumentando el número de la Corte local de tres a cinco miembros10. Hacia finales del año 2002,

\footnotetext{
7 Sin pretender hacer un examen excautivo del texto constitucional, mostramos a manera de ejemplo los Institutos que se incorporaron al texto constitucional: la Fiscalía de Asuntos Administrativos, el Consejo Económico y Social y el Defensor del Pueblo. Se incorporan los derechos para los Pueblos Originarios, se protege el medio ambiente y recursos naturales, se consagran los derechos a los consumidores y usuarios, las amas de casa, amparo a las madres solteras desprotegidas, entre otros.

8 La construcción de la hegemonía partido-Estado, es liderada por la elite dirigente del Partido Justicialista local, en la que partido gobernante y Estado se mezclan, se fusionan y se conjugan con la impronta de conducciones personalistas desde el Poder Ejecutivo Provincial (PEP), apoyada por dicha elite, en articulación con grupos empresariales, vinculados a la ganadería, a la construcción, empresariado forestal, comercial, gremial, partidos políticos y organizaciones sociales a los cuales abre la posibilidad de ocupar espacios de poder a nivel Legislativo, o Ejecutivo. Política y electoralmente, se forja a través de una herramienta clave: la Ley Provincial n. 657 sancionada el 1 de abril del año 1987 (que irá incorporando algunas modificaciones), conocida como Ley de Lemas.

${ }^{9}$ El Artículo 129 había habilitado al Gobernador Vicente Joga en 1991, a una reelección de su mandato, participando de la fórmula nuevamente como Vicegobernador Gildo Insfrán. Ello le permitió a este último, sucederlo por un nuevo período (1995-1999) como Gobernador. A hora bien, como Insfrán ya había sido reelecto sucediendo al anterior Gobernador. Para 1999, según el Artículo en cuestión, no estaba habilitado para presentarse a una nueva elección para ninguno de ambos cargos, sino con el intervalo de un período. Esta limitación, es la que será sometida a la interpretación del Superior Tribunal de Justicia, quien con dos votos a uno negativo convalidó la decisión en un ambiente de gran presión política sobre los integrantes del Poder Judicial de la provincia.

${ }^{10}$ Gabriel Sued (2006). Diario La Nación 04/12/2006.
} 
se hacía evidente que el Gobernador buscaba una nueva reelección, en un ambiente social y económico convulsionado, dramático y teñido por las emergencias económicas, a raíz de la situación de crisis que transcurría en el país y a nivel provincial.

Ese escenario, a su vez, fue crucial para la construcción de una arquitectura de leyes y arreglos escalares verticalizantes que facultarán con amplios poderes al PEP para decidir sobre el patrimonio del Estado ${ }^{11}$. Junto a este plexo normativo, se prorrogan las Leyes de Emergencia Económica n. 1.296 y 1.342 que se habían puesto en vigencia desde 1991, las que tendrán una continuidad sistemática a través la sanción de las leyes nacionales y provinciales que la prorrogarán, durante todo el período analítico ${ }^{12}$.

En ese escenario, la amplia mayoría de diputados oficialistas en la Legislatura que seguía la marcha incesante del PEP en la acumulación de mayores atribuciones, terminó entonces, facilitando la declaración de necesidad de la reforma constitucional, abriendo los comicios a tal efecto, el 1o de junio de 2003.

Un elemento clave que no puede soslayarse en este proceso, es la aparición en este escenario político provincial del Presidente Néstor Kirchner, quien había asumido como primer mandatario de la Nación, el 25 de mayo de dicho año. El 28 de ese mes, a solo cuatro días de los comicios para la elección a Convencionales Constituyentes, el Presidente de la Nación arriba a Formosa manifestando su apoyo al proceso político que se encontraba desarrollando y al Gobernador Insfrán, con la firma junto al PEP del Acta de Reparación Histórica-ARH ${ }^{13}$.

De esta manera, tras ganar las elecciones el Partido Justicialista con el 56\%, se instituye el ambiente de la reforma constitucional con amplia mayoría de dicho partido político, que impondrá la reelección ilimitada para todos los cargos electivos ${ }^{14}$, lo que le permitirá a Gildo Insfrán acceder a su tercer (2003-2007) y luego a un cuarto mandato (2007-2011), continuando de manera ininterrumpida en el período (2011-2015) a la actualidad. Desde la reforma de 1991 a la de 2003, se centraliza el poder en el PEP ${ }^{15}$, se debilitan el Poder Judicial y el Poder Legislativo ${ }^{16}$ con pérdida de protagonismo de este último.

Podremos observar entonces, en un escenario de arreglos escalares verticalizantes y hegemónico, que el funcionamiento de dicha plataforma como bien lo señalan Peck y Tickell originó un doble vínculo entre las escalas ${ }^{17}$ territoriales local/global - en tanto espacios

\footnotetext{
${ }^{11}$ Se trata de la Ley n. 1.367 que adhiere a la Ley Nacional de emergencia económica n. 25.561. Con ello, se le otorga al PEP poderes extraordinarios (Art. 10) donde se lo faculta a realizar todas las acciones, trámites, convenios, suscribir documentación, etc. que resulten necesarios, pudiendo, entre otras, modificar plazos, intereses, modalidades de pago, montos, etc. de las operaciones originales, comprendiendo las mismas los títulos públicos, bonos, letras de tesorería, préstamos, contratos de fideicomiso, etc., así como su negociación, canje, operaciones de pase, afectación en garantía, y/u otras modalidades de operaciones financieras conforme a los usos y condiciones de mercado, del modo que resulte más favorable para el fisco y la economía provincial. Se lo faculta a refinanciar y reprogramar las acreencias de cualquier naturaleza del Estado Provincial que se mantenga con distintos Organismos Oficiales y/o Entidades Autárquicas, Centralizadas, Descentralizadas, y/o persona física o jurídica.

${ }^{12}$ Así por ejemplo a través de la Ley Provincial n. 1.576 adhiere la Provincia de Formosa a la Ley Nacional n. 26.729 que prorroga la vigencia de su similar n. 26.204, prorrogada a su vez por las Leyes n. 26.339, 26.456 y 26.563 hasta el 31 de diciembre de 2013, que son las prórrogas de la Ley n. 25.561. Simultáneamente, a nivel meso regional se prorrogan la vigencia de las Leyes Provinciales $n$. $1296,1342,1472,1367,1485,1503,1518,1530$ y 1544 como asíl la de todas las normas reglamentarias y aclaratorias dictadas en su consecuencia, manteniéndose el "estado de emergencia pública" durante el término establecido en la mencionada Ley Nacional.

${ }^{13}$ El ARH implicó para Formosa, la percepción de un volumen de flujo de fondos provenientes del Estado nacional con destino a múltiples infraestructuras, que se detallan en el PET Formosa 2015, las que se ejecutaron desde 2005.

${ }^{14}$ Abarcan los del Poder Legislativo, Ejecutivo y los Municipios. Art. 105; 132 y 179 Constitución Provincial de 2003.

${ }^{15}$ Véase los Artículos n. 62 y 65, de la Constitución Provincial.

${ }^{16}$ Véanse el Artículo 120 Incisos 4 y 5 y el Artículo 170 Inciso 6.

${ }^{17}$ Se interpretan a las escalas como representaciones impulsadas por los actores académicos, institucionales y económicos, que
} 
estratégicos del desarrollo:

[...] Los ámbitos locales se encuentran determinados por las dinámicas globales y lo local es resignificado como configurador de los procesos globales. Sin embargo, esas relaciones son asimétricas e inestables - y más aún en territorios periféricos-, porque las estrategias locales, al favorecer la libertad de acción del capital, se inclinan a la voluntad de la competencia global. (PECK; TICKELL, 1994, p. 285)

Asimismo, entre las regiones se alientan relaciones competitivas que consolidan y acentúan los procesos fragmentarios de reproducción socioespacial y, de este modo, provocan nuevos desequilibrios y desigualdades.

Hacia finales del año 2001 llegó a su clímax la crisis del proceso neoliberal. Esto implicó un giro hacia una revalorización de la autonomía relativa del Estado para orientar el desarrollo económico capitalista. En tal sentido, por lo menos algunas de las características más ostensibles de las políticas macroeconómicas del paquete de medidas del neoliberalismo de retracción, se dejaron de lado.

No obstante, ello no implicó que el neoliberalismo haya perdido su esencia, dando lugar a otro régimen de regulación distinto. La interpretación de un supuesto fin del neoliberalismo en Argentina (y en varios países latinoamericanos) inclusive, se trasladó al ámbito mundial después de la crisis económica global de 2008. Sin embargo, Brenner, Peck y Theodore (2010, p. 22) sugieren por el contrario, que: "más que la sentencia de muerte para el neoliberalismo, podemos estar viendo otro punto histórico de inflexión del mutante proceso de neoliberalización".

En efecto, estos autores criticando las posturas que sostienen su muerte, ponen el acento en la deficiente conceptualización del "sistema regulatorio" al que se denomina "neoliberalismo". La noción analítica clave que ellos postulan, es la de pensar al neoliberalismo como un proceso de neoliberalización, que como un estado o condición final. Así, entienden que la neoliberalización es un proceso cambiante, evolutivo y plástico, cuyo núcleo reside en: "la movilización del poder estatal para extender el dominio del mercado" (PECK; TICKELL, 2003, p. 166).

Esa movilización del poder estatal en la que se mimetiza y extiende el dominio del mercado, se desarrolla a través de procesos de re-escalonamientos y territorialización ${ }^{18}$. El primero explica PECK (2010, p. 91): "genera la recombinación, reorganización y reconstitución de funciones y de relaciones escalares, en lo institucional, y regulativo"; para Swyngedouw (2010, p. 56-7) el segundo: "produce una configuración socio-espacial disputada. Constituyendo la arena donde se liberan las batallas por el control y el empoderamiento del espacio social".

Al respecto, el ingreso e institucionalización de la NOR en Formosa y sus localidades, inició sus primeras experiencias de re-escalonamiento y territorialización hacia mediados y fines de los noventa, con dispositivos fragmentarios como el proyecto del desarrollo del Centro-Oeste y la propuesta del Bosque Modelo Formoseño como presentamos en el Cuadro n. 1 y luego analizaremos en la siguiente sección.

Esos procesos se amplifican desde el año 2004, con la implementación en Argentina del Plan Estratégico Territorial (PET) coordinado por el Ministerio de Planificación Federal Inversión y

despliegan estrategias destinadas a resolver su reproducción y los conflictos de poder a los que esas estrategias dan lugar. Ello conlleva el posicionamiento de una determinada organización espacial de las dinámicas económicas, sociales e institucionales y, a partir de ello, una configuración dada de las escalas -globales, nacionales y locales-y sus vínculos, en concordancia con esas estrategias (FERNÁNDEZ; VIGIL; SEVAL, 2012, p. 28).

${ }^{18}$ La reterritorialización y la desterritorialización, son las transformaciones del espacio en sentido expansivo o contractivo respectivamente, derivados de las dinámicas escalares en tanto conflictos de poder, entre los distintos grupos sociales y sus estrategias de cooperación y competencia, haciendo surgir configuraciones con escalas nuevas que delimitan nuevas fronteras. 
Servicios Públicos, a través de la Subsecretaría de Planificación Territorial de la Inversión Pública ${ }^{19}$, donde todas las jurisdicciones provinciales se articularon desde una metodología homogénea, lineamientos e iniciativas de impacto territorial. Por su parte, el Consejo Federal de Inversiones con su línea de trabajo sobre Planificación Estratégica Regional20, asiste y acompaña las experiencias en los municipios con los Planes Estratégicos de Desarrollo Local (PEDL).

Cuadro 1 - Institucionalización de la NOR, en la región Centro-Oeste de Formosa

\begin{tabular}{|c|c|c|}
\hline Instituciones Líderes & Escala Meso Regional & $\begin{array}{c}\text { Escala Micro Regional o Local del } \\
\text { Centro-Oeste }\end{array}$ \\
\hline & \multicolumn{2}{|c|}{ Estrategia - Programas de Competitividad y Cluster } \\
\hline $\begin{array}{l}\text { - Ministerio de la Producción y } \\
\text { - Ambiente de Formosa. } \\
\text { - Banco Interamericano de } \\
\text { Desarrollo (BID). } \\
\text { - Instituto de Colonización y } \\
\text { Tierras Fiscales } \\
\text { - Ministerio de Economía y } \\
\text { Finanzas Públicas. Secretaría de } \\
\text { Política Económica de la Nación. } \\
\text { - Ministerio de Economía de } \\
\text { Formosa Universidad Nacional de } \\
\text { Formosa. } \\
\text { - Programa de Servicios Agrícolas } \\
\text { Provinciales(PROSAP) }\end{array}$ & $\begin{array}{l}\text { - Proyecto de desarrollo del } \\
\text { Centro-Oeste. } \\
\text { - Programa de Competitividad } \\
\text { de Norte Grande (PCNG): } \\
\text { Plan de Competitividad del } \\
\text { Conglomerado Bovino de } \\
\text { Formosa. } \\
\text { - Plan de Colonización y } \\
\text { Ordenamiento Territorial y } \\
\text { Catastral de la tierra Pública. } \\
\text { - Plan de Mejoramiento de la } \\
\text { Competitividad (PMC) - Cluster } \\
\text { Acuícola del NEA y frutícola } \\
\text { NOA con aportes de CEDEVA }\end{array}$ & $\begin{array}{l}\text { En el Plan Estratégico Formosa } \\
2015 \text { se encuentran las regiones: } \\
\text { Centro Oeste y Extremo Oeste. } \\
\text { Las que forman parte de las } \\
\text { Macro Regiones: } \\
\text { - Central } \\
\text { - Centro- Oeste }\end{array}$ \\
\hline \multirow[b]{2}{*}{$\begin{array}{l}\text { - Red Regional de Bosques } \\
\text { Modelos para América Latina y el } \\
\text { Caribe (CRBM-LAC). } \\
\text { - Agencia Internacional de } \\
\text { Cooperación Japonesa (JICA) } \\
\text { - Programa Nacional de Bosque } \\
\text { Modelo. } \\
\text { - Ministerio de la Producción y } \\
\text { - Mmbiente. } \\
\text { - } \text { Juáricipalidad de Ingeniero } \\
\text { - Universidad Nacional de } \\
\text { Formosa. } \\
\text { - CEDEVA. } \\
\text { Equipo de Promoción y } \\
\text { Acompañamiento Solidario } \\
\text { (PRASOL) }\end{array}$} & \multicolumn{2}{|l|}{ Bosque Modelo Formoseño - BMFo } \\
\hline & & $\begin{array}{l}\text { El BMFo opera en la localidad } \\
\text { de Ingeniero Juárez. Es una } \\
\text { Asociación Civil sin fines de } \\
\text { lucro creada en el año } 1998 \\
\text { obteniendo su personería jurídica } \\
\text { en } 2004 \text {. Su área de incidencia: } \\
800 \text { mil hectáreas, poblada por } \\
45 \text { mil habitantes donde viven } \\
\text { criollos y aborígenes (tobas } \\
\text { y wichis). Busca el desarrollo } \\
\text { sustentable de los ecosistemas } \\
\text { boscosos, elevar el nivel y calidad } \\
\text { de vida de las comunidades o } \\
\text { asentamientos, de bajos recursos } \\
\text { (BOSQUE MODELO, 2010). }\end{array}$ \\
\hline
\end{tabular}

\footnotetext{
${ }^{19}$ El objetivo desde 2004 era concretar inversiones públicas y de equipamiento, a través de una metodología homogénea de articulación y consensos entre organizaciones públicas, civiles y económicas, extendiéndose hasta el año 2016. Desde el año 2015, la subsecretaría funciona en el ámbito del Ministerio del Interior, Obras Públicas y Vivienda.

${ }^{20}$ La entidad apoyó con financiamiento los PEDL en el territorio de Formosa, bajo la coordinación, de la Fundación Arandú de la Provincia de Corrientes.

${ }^{21}$ La entidad financia proyectos a través de la inversión pública directa articulada con el sector privado e iniciativas de mejora competitiva. Dinamiza a su vez, las Iniciativas de Desarrollo de Cluster (IDC). (http://www.prosap.gov.ar).

${ }^{22}$ Es el Centro de Validación Tecnológica Agropecuaria. Su objetivo es producir información disponible para empresarios que se proponen invertir en la región Oeste y Centro-Oeste. Les ofrece paquetes de tecnología que se adaptan a dichas regiones para la agricultura o la ganadería (https://www.formosa.gob.ar/cedeva).
} 


\begin{tabular}{|c|c|c|}
\hline Instituciones Líderes & Escala Meso Regional & Centro-Oeste \\
\hline & \multicolumn{2}{|c|}{ Plan Estratégico Territorial y Planes Estratégicos de Desarrollo Local } \\
\hline $\begin{array}{l}\text { - BID } \\
\text { - PNUD Argentina. } \\
\text { - Ministerio de Planificación } \\
\text { Inversión Obras y Servicios } \\
\text { Públicos de la Nación. } \\
\text { - Consejo Federal de } \\
\text { Inversiones(CFI). } \\
\text { - Fundación Arandú - Provincia de } \\
\text { Corrientes. } \\
\text { - Ministerio de Planificación } \\
\text { Inversión Obras y Servicios } \\
\text { Públicos de la Formosa. } \\
\text { - Dirección de Planificación del } \\
\text { Desarrollo Local de Formosa. } \\
\text { - Municipios Seleccionados. }\end{array}$ & $\begin{array}{l}\text { Referencias Teóricas de los plan } \\
\text { manuales de CEPAL-ILPES y Cad }\end{array}$ & $\begin{array}{l}\text { Los Planes Estratégicos de } \\
\text { Desarrollo Local - PEDL - fueron } \\
\text { realizados en } 25 \text { Municipios } \\
\text { seleccionados por la Provincia. } \\
\text { Aquí mencionamos, a los de la } \\
\text { región Centro-Oeste: } \\
\text { 1) General Güemes } \\
\text { 2) Ibarreta } \\
\text { 3) Estanislao del Campo } \\
\text { 4) Ingeniero Juárez } \\
\text { 5) General Enrique Mosconi } \\
\text { 6) Pozo de Maza } \\
\text { s: basadas en documentos y } \\
\text { la de Valor de base Porteriana. }\end{array}$ \\
\hline $\begin{array}{l}\text { Agencia d } \\
(A D E)^{26} F C\end{array}$ & \multicolumn{2}{|c|}{$\begin{array}{l}\text { - Feria Internacional de Mueble y la Madera (FEDEMA) Formosa } \\
\text { - Feria Internacional de Frutos Argentinos (FRUTAR) Formosa } \\
\text { - Programa de Entrenamiento Gerencial Para Empresas Industriales } \\
\text { - Programa de Visita y Apoyo a Empresas } \\
\text { - Programa de Acceso al Crédito y la Competitividad } \\
\text { - Programa Fondo Nacional para el Desarrollo de la Micro, Pequeña y } \\
\text { Mediana Empresa (FONAPYME) } \\
\text { - Programa Capital Semilla }\end{array}$} \\
\hline
\end{tabular}

Fuente: Elaboración propia en base a fuentes documentales de Organismos Oficiales de la Provincia de Formosa.

Se aprecia en el Cuadro, el detalle de las instituciones que lideran el proceso, proveniente de organismos internacionales, financieros supranacionales, Instituciones gubernamentales y no gubernamentales en dicho espacio territorial. También se puede observar, el conjunto de dispositivos de políticas fragmentarias que operan en las distintas escalas del territorio, reflejados a través de los Programas, proyectos, planes de competitividad, iniciaciones de clusters, plan estratégico territorial, planes estratégicos de desarrollo local, programas feriales, de entrenamiento gerencial y de financiamiento al empresariado.

Esos dispositivos tienen como principio rector, la construcción inspirada en las líneas envasadas en el pensamiento único localista de base participativa, universales y comunitarista, con eje para el desarrollo en la escala local para la inserción global.

La conjunción de esos dispositivos y principio rector, comienzan a configurar el patrón regulativo escalar que viene a recrear formas de intervención estatal asimilables a la neoliberalización. Es decir, refuerzan el re-escalonamiento espacial hacia abajo basado en la descentralización y la relativización de la escala nacional a través esos dispositivos fragmentantes, pero también desarticulan las tensiones sociales - como se observará en la segunda parte - que producen las redes del capital, impulsando hacia el interior de la microescalas de territorios en disputa, un mensaje de construcción horizontal y participativo, que termina siendo funcional a esos intereses.

\footnotetext{
${ }^{23}$ La JICA, tiene como fin contribuir a la promoción de la cooperación internacional y apoya al desarrollo socioeconómico, la recuperación o la estabilidad económica de los países en desarrollo (http://www.jica.go.jp/spanish/index.html).
} 
Ese mensaje cuando es aceptado acríticamente, implica a cambio, la subordinación a una rejerarquización de las escalas subnacionales como espacios capaces de moldear su propia dinámica de desarrollo, a partir de la articulación asociativa y cooperativa de actores económicos e institucionales, cohesionados y autorresponsables de su inserción en el escenario global.

Se vectoriza, así, una nueva arquitectura regulatoria denominada Peck y Tickell (2007, p. 33) el "roll out" o arreglos escalares consensuados de la neoliberalización; esto es, el despliegue de: "nuevas formas estatales, nuevos modos de regulación, nuevos regímenes de gobernanza, con el objetivo de mediar y consolidar tanto la mercantilización como sus consecuencias".

Son estas formas regulativas las que se dinamizan en Formosa en el marco del MFDP. Un ambiente de territorialización-reterritorialización, donde los definidores de política que lideran las instituciones estatales, en un complejo entramado regulativo median acuerdos para que las fracciones del capital accedan a la liberación de un conjunto de activos como los recursos naturales del Centro-Oeste, incluida la fuerza de trabajo a un coste muy bajo. Esa dinámica regulativa es la que a su vez va ir adquiriendo durante el tiempo espacial en estudio, nuevas características que buscan reposicionar el poder del Estado con mayor injerencia en esta actividad. Sin embargo, no modificará la atmosfera dominante extractivista que en términos de Harvey (2004, p. 113) desarrollan procesos de "acumulación por desposesión".

La acción estatal a escala regional/local se dirige así, a establecer nuevos marcos institucionales para movilizar las fuerzas productivas con relación a la reterritorialización del capital; a promover la competitividad al incentivar, crear, mantener y realzar fuerzas productivas específicas, y a regular las contradicciones sociopolíticas de la dinámica del capital (BRENNER, 2003). Es decir, cambia la modalidad de intervención estatal (y el sostenimiento estatal) por la modificación de la lógica y la dinámica espacial de la acumulación del capital. Surge un Estado, destinado a dar soporte al desarrollo de procesos productivos y ser articulador de múltiples intereses público-privados, necesarios para ligar esos procesos con la generación y transferencia de conocimientos.

Peck y Tickell (1994) señalan, también, sobre los límites que se generan cuando la regulación y las políticas públicas son planteadas exclusivamente desde la instancia local/regional - las cuales se hallan entregadas a la dinámica del capital global móvil y a la competencia por las fracciones de capital - ya que estas por si solas tienen poco poder político para poder conducir esos procesos en un contexto de acumulación global y desregulado ${ }^{24}$. En el mismo sentido JESSOP (2008) observa, que las instancias estatales subnacionales desprovistas de una articulación con el Estado-nación - que dispone de una base fiscal para realizar modificaciones en esos ámbitos -, no pueden por sí mismas generar transformaciones sustantivas en esas materias.

Estos elementos analíticos, permiten notar que la reestructuración morfológica, el desarrollo de nuevas funciones y el modo de intervención del Estado, implican un reacomodamiento de la forma de organización del poder y de las relaciones entre los actores, que influye en la definición de sus políticas y en cómo se ejercen. Se añade a esto otro aspecto relevante, la redefinición de las funciones del Estado-nación, cuya centralidad estratégica se mantiene, pero reformulada y reestructurada por la proliferación de las escalas y sus dinámicas, readaptadas a la nueva lógica de acumulación y reproducción del capital y de su impacto en los territorios. Teniendo en cuenta estas formas de organización e implicación estatal, se observarán, a partir de aquí, el proceso

\footnotetext{
${ }^{24}$ Los ámbitos locales poseen responsabilidad sin poder y las instancias supranacionales poseen poder pero sin responsabilidad por las consecuencias sociales y económicas (PECK; TICKELL, 1994). Para lo cual agregamos, a los que se les giran recursos y "carecen de toda responsabilidad democrática real" (JESSOP, 2008, p. 261).
} 
de plegamiento de las políticas públicas fragmentarias que se pliegan a las lógicas de intereses y sus estrategias, desplegadas en el espacio del Centro-Oeste.

\section{LAS POLÍTICAS PÚBLICAS FRAGMENTARIA Y SU DESPLIEGUE EN EL CENTRO-OESTE}

Se presentan aquí, en primer término, los elementos constitutivos y emergentes de las estrategias de políticas fragmentantes en el espacio del Centro-Oeste de Formosa ${ }^{25}$, las que luego permiten adentrarse en el análisis de su desenvolvimiento en dicho territorio.

Entre los primeros elementos de importancia, se encuentran un conjunto de marcos legales que operan afectando las tierras con destino a la radicación de inversiones (Ley provincial $\mathrm{n}$. 1.137) y de venta especiales de tierra (Leyes provinciales n. 1.218 y 1.321). A estas leyes, se les adicionan espacios institucionales de articulación público-privado, proyectos, programas y planes ya aludidos en el Cuadro n. 1 e infraestructuras, como el Canal de agua a cielo abierto Laguna Yema-Las Lomitas; las destinadas a regular los ciclos de desborde y sequia del Bañado la Estrella, la construcción de caminos pavimentados y tendido de redes eléctricas.

Dichos elementos articulados darán forma, al patrón regulativo escalar y de infraestructuras, que se presenta hacia mediados de los años 1990, como una respuestas alternativa al proyecto neoliberal de ajuste estructural, pero sin embargo como se observará, su dinamización estrategia espacial, se funcionaliza a la lógica de co-producción de políticas con los actores regionales, que imponen una extensión de los procesos de mercantilización de la tierra y la explotación de recursos naturales, a través de una implicación estatal que facilita un renovado y más complejo proceso de desarticulación fragmentante al momento de implicar la dinámica regional, motorizando la idea del desarrollo con eje en lo regional/local-global.

Esa lógica que opera en el denominado "anclaje del Centro-Oeste" (GIULIANO, 2015, p. 147) ha generado, como segundo elemento de importancia, la selectividad y penetración de actores económicos vinculados a capitales nacionales y extranjeros, que usufructúan el patrón aludido, produciendo espacios de acumulación extractivistas-primarizados. Esa dinámica relacional se encuentra vinculada por una parte, al proceso de corrimiento de la frontera productiva sojera en las regiones pampeanas y extra-pampeanas y a la pamperización de la ganadería ${ }^{26}$, que permitió que la producción pecuaria y otras actividades agrícolas alternativas, se desplazaran al territorio formoseño del Centro-Oeste. Simultáneamente a estos procesos de acumulación extractivista, un tercer elemento emergente, es la fragmentación espacial y la disputa por los recursos naturales, involucrando a actores locales diversos y la manifestación de asimetrías notorias en lo social, político y económico.

Entre esos actores locales, se hallan, por una parte, las asociaciones de las comunidades indígenas y pequeños productores, que denuncian al Estado por las infraestructuras de control del agua. A ellos se suman otras comunidades originarias afectadas por los desmontes, a raíz de

\footnotetext{
${ }^{25}$ El área de características semiáridas, tiene una superficie total 2,5 millones de hectáreas, cuyos límites son: al Oeste la línea Barilari, que establece el límite con la Provincia de Salta-Argentina, al Norte con el Río Pilcomayo y la República del Paraguay, al Sur con el Río Bermejo y al Este con la Ruta Provincial n. 26. Este perímetro, incluye a la totalidad de los departamentos Bermejo, Ramón Lista y Matacos y una porción del departamento Patiño delimitada por ruta provincial mencionada (Ministerio de la Producción, Provincia de Formosa, 11 de octubre de 2018).

${ }^{26}$ Entre los Censos Agropecuarios de 1988 y 2002, las provincias que mayor expansión tendrán en el cultivo de la soja serán las comprendidas en la región pampeana: Buenos Aires, Santa fe, Córdoba y norte de La Pampa y entre las extra-pampeanas: Entre Ríos, Santiago del Estero, Chaco y Salta. Azcuy Ameghino y Ortega (2016, p. 155). Dicho proceso no se detendrá en nuestro período de estudio. A su vez, la expansión de la ganadería ha sido acompañada de un cambio en la cría e invernada que el predominante hasta entonces (de tipo extensivo), utilizando medios tecnológicos que permitieron la adaptación del ganado a las condiciones agroecológicas del territorio (Lo escrito en cursiva es nuestro).
} 
la presión ganadera, agrícola, forestal que provocan los capitales extranjeros y nacionales que se instalan, así como por las megainversiones proyectadas e iniciadas en el Centro-Oeste, que van modificando el espacio habitado por estos pobladores.

Por otra parte, se encuentran las asociaciones promovidas por el Estado provincial a través del Plan piloto de afincamiento de explotaciones ganaderas con sistema silvo-pastoril27; el Plan de Competitividad del Conglomerado Ganadero Bovino y las surgidas en articulación con Agencias globales, como el Modelo Bosque Formoseño. Se tratan de experiencias, que se funcionalizan en las ideas del pensamiento único localista, para moldear su propia dinámica espacial de desarrollo.

En efecto, los primeros elementos presentados se visualizan hacia 1994, cuando se concretiza el Proyecto de Aprovechamiento múltiple del Río Teuco-Laguna Yema, basado en la construcción del canal de agua abastecido desde el río Bermejo. Esta infraestructura, contará con otros dos pilares institucionales, que le darán coherencia estructural: 1) el primer CEDEVA inaugurado en la localidad de Laguna Yema ${ }^{28}$ y 2) la Ley Provincial n. 1.137.

En esta articulación espacial, a los laterales del canal a cielo abierto de 96 kilómetros de longitud desde Laguna Yema hasta Las Lomitas, se empezarán a radicar las empresas, incentivadas además por las obras de pavimentación del tramo faltante de la Ruta Nacional 81 entre los años 2004-2008 y la llegada de la interconexión eléctrica y los beneficios del régimen de diferimiento e incentivos impositivos.

El CEDEVA, a su vez, comienza a incursionar en el contenido tecnológico. Así en 1998 importará la experiencia israelí de sistemas de riego por goteo y por aspersión, que serán instalados y supervisados a través de técnicos llegados de este país. Dichos sistemas serán utilizados luego, por los principales grupos empresariales instalados en la región.

Con la Ley Provincial n. 1.137 de 1994, se delimita el área para el afincamiento de los inversores de aproximadamente unas 100 mil hectáreas, se reservan en ella, las tierras de dominio de la provincia colindantes a los canales construidos en los Departamentos de Ramón Lista, Matacos, Bermejo y Patiño, abarcando una superficie que se determinará en base a los 5 kilómetros que se cuentan desde ambas márgenes y a lo largo de todo el recorrido de los canales, (Art. 1). En este marco, el Poder Ejecutivo provincial fija las condiciones en que se efectuará la venta de las tierras, comprendidas en la reserva y los planes para su colonización, sujeto a aprobación del Legislativo (Art. 2).

Esta atmósfera creada hace evidente a partir de 1996 la instalación de sociedades empresariales agrícola-ganadero de capitales extranjeros y nacionales. El caso emblemático, se formaliza con la venta de 40 mil hectáreas de tierras fiscales a L.I.A.G. Argentina S.A de capitales australianos, a través de la Ley Provincial n. 1218 de dicho año.

Según constata Giuliano (2015, p. 148), van instalándose hacia ambos lados del canal, las empresas Cotton Saurer SA, Unitec Agro S.A.-Grupo Eurnekian, Sumayen S.A, Agrocit S.A., Ciagro S.A., Laguna del Oeste S.A., Tejerina, Virasol S.A., Alma Gaucha y Cabañas Nuevo Milenium. Las actividades principales de estos capitales de origen extranjero y nacional extra provinciales, gira en torno a los agronegocios, la ganadería bobina-bufalina y la cría de caprinos de raza y producción de semen, todos con destinos exportables a países del continente y la Unión Europea entre otras.

\footnotetext{
${ }^{27}$ Se trata de la columna vertebral del Programa de Colonización y Ordenamiento Territorial y Catastral de la tierra Pública, realizado en el Instituto de Colonización y Tierras Fiscales de Formosa el 11 de enero de 2006.

${ }^{28}$ Es la Ciudad cabecera (es decir, con estatus de municipalidad), ubicada en el departamento Bermejo al Oeste de la provincia de Formosa.
} 
En los años 1999 y 2000, el Estado Provincial avanza en la venta de tierras a favor de: La Florencia y Ganadera Balado. El primero es un establecimiento privado de 60.000 hectáreas, sobre la Ruta Provincial n. 39, frente a la provincia de Chaco sobre el río Bermejo y colindante a la zona de influencia del Canal que toma el agua de dicho río y lo conduce a las localidades de Ingeniero Juárez - Los Chiriguanos en el Departamento Matacos. El proyecto busca la reforestación de quebracho blanco y colorado, algarrobo timbó, viraró y guayacán y en veinte años el inicio de la producción.

El segundo corresponde a la venta de una superficie de 6.614 hectáreas en el Departamento Patiño, a través de la Ley provincial n. 1.321 del año 2000, a favor de Daniel Alberto Balado, propietario de la empresa ganadera del mismo nombre.

Estas decisiones de política han desarrollado tensiones y conflictos, al afectar tierras históricamente ocupadas por pequeños productores y/o comunidades indígenas, lesionando los derechos de dichas poblaciones.

Al respecto, la solución mediada del Estado Provincial a estos problemas, ha sido errático y a favor de los dueños del capital. En efecto, estas han ido desde: 1) la implementación de programas de reubicación de productores a 2) la inacción declarativa de ser un amigable componedor.

El primero correspondió al caso L.I.A.G. S.A. Dicho programa reubicó a los pequeños productores e indígenas en pequeñas parcelas, con el compromiso de parte de la empresa, en realizar una serie de mejoras que luego serán reconocidas por parte del Estado en términos de beneficios a favor la firma extranjera. A cambio esta última, construirá al inicio algunas viviendas del programa PAIPPA ${ }^{29}$.

El segundo se refiere al caso La Florencia S.A.; allí, el Estado permitió a la empresa a actuar con libertad en la propiedad, donde ya vivían familias de pueblos originarios. Otros viven en puestos rurales y se dedican a la producción ganadera de ganado bobino y caprinos.

La tensión y el conflicto se generaron, cuando los propietarios de la firma avanzaron sobre las propiedades de estos pobladores, lo que ocasionó la resistencia de estos últimos. La postura del Estado, frente a estos hechos fue manifestar su desentendimiento, declarándose ser un amigable componedor. Así lo expresaba el definidor de políticas del Instituto de Tierras Fiscales de la Provincia ${ }^{30}$ :

[...] La estancia la Florencia [...] hasta 1903 o 1904 era propiedad de Bunge y Born [...] luego paso por varias manos, inclusive fue de un tal Martínez de Hoz hasta 1970, y hace unos años fue adquirida por un hombre de apellido Bellsola... El campo fue vendido varias veces siempre para especulación financiera... el nuevo propietario, un tal Bellsola, hablo conmigo hace un año y le dije: vos compraste un problema, un campo con toda la gente adentro, por lo tanto el problema es tuyo con la gente, no sé cómo va a terminar esto, pero tiene más validez la gente que vive allí. El organismo que dirijo solo interviene como amigable componedor.

Mientras estos procesos se encuentran desplegándose. Por otra parte, producto de los desbordes cíclicos que el río Pilcomayo genera sobre el Bañado la Estrella, el Estado avanzará en 1997 en la construcción de infraestructuras de manejo del agua31, que buscaban derivarla a Las

\footnotetext{
${ }^{29}$ En 1996 al adjudicarse las tierras a LIAG S.A., los pobladores que estaban asentados históricamente en ella serán ubicados en parcelas de 10 a 15 hectáreas aledañas a la empresa. Para ello, se afectaron 101 mil hectáreas. La empresa se encargó de la construcción de 16 represas, $124 \mathrm{~km}$ de picadas interlotes, $67 \mathrm{~km}$ de picadas (caminos de accesos internos) y 107 has de desbarejado. El costo de todo ello, fue reconocido por el Estado y depositado en la cuenta corriente de la Empresa (BOBADILLA DE GANE; SILVA, 2004).

${ }^{30}$ Diario El Comercial, Formosa, Argentina, en 12 de septiembre 2008.

${ }^{31}$ La obra financiada con fondos del Banco Interamericano de Desarrollo (BID) y apoyado por el Estado Nacional, consistió en un terraplén sobreelevado sobre las dos cuencas: la del río Salado y la del Bañado La Estrella. Usando como traza a la Ruta Provincial-RP n. 28. Esta elevación oscila según las zonas, desde los 0,70 metros en la parte norte, hasta unos 5 metros en la zona de El Salado. El terraplén interrumpe en parte la dinámica cíclica y amplía considerablemente la zona que ahora permanece
} 
Lomitas, zonas aledañas y campos próximos, donde se pretendía desarrollar actividades productivas.

Esas decisiones fueron interpretadas como violaciones a los derechos de los pueblos originarios y de los pequeños productores32, los que impulsaron una serie de denuncias que intentaron frenar la construcción.

Las tensiones se acrecentaron y el año 2005 se promulga la Ley Provincial n. 1.471 a través de la cual el Estado declara de dominio público al Bañado La Estrella más lo que pudiera incrementarse a futuro, apelando al argumento del cuidado y preservación del agua dulce y de las condiciones ambientales del lugar. No obstante, ello no detuvo los reclamos y pedidos de inconstitucionalidad ${ }^{33}$ de los pobladores afectados - aunque sin éxito -, quienes interpretaban el avance confiscatorio del Estado sobre las tierras comunitarias indígenas y propiedades de productores - incluidas las adjudicadas en venta en tanto derecho adquirido para su titularización -, con destino al desarrollo clusterizado de producción bovina y agrícola como anticipáramos en el Cuadro n. 1.

Esa percepción de las comunidades indígenas y los pequeños productores, no resultaba improvisada. Si se observa el Cuadro n. 2 y se hace foco en el desenvolvimiento de las hectáreas implantadas de hortalizas y de las forrajeras de importancia singular para la región del Centro-Oeste, dado que los demás grupos de cultivo no se desarrollan en esta región, se puede apreciar que:

Las hortalizas no solo que poseen la menor participación en el total de las superficies de la $\mathrm{EAP}^{34} \mathrm{~S}$ implantadas en el último censo sino que a su vez comparativamente al CNA del 2002; en 2008 sufren una caída importante del 55\%. Esas condiciones agudizarán la dependencia con los programas focalizados impulsados desde el Estado hacia los pequeños productores ${ }^{35}$. En este escenario, la horticultura mostrará una estructura en torno a dos conjuntos productivos diferenciados; por un lado, una gran cantidad de pequeños productores, que tradicionalmente desarrollan prácticas hortícolas combinando la orientación al mercado y el autoconsumo, por el otro, un reducido número de nuevas empresas hortícolas, capitalizadas con mejores tecnologías, cuyo objetivo es generar producción con escala y destino exportador ubicadas en el anclaje del Centro-Oeste, y otras en el Centro-Este de Formosa, cuya actividad busca abastecer el mercado interno y Buenos Aires (ARGENTINA, 2009, p. 64).

constantemente inundada al oeste de dicha ruta (BROWN et al., 2010, p. 104).

32 Desde el inicio y hasta la finalización de las obras en 2007, la Federación Pilagá, la Asociación de Productores del Bañado La Estrella (APROBAE), junto a la Fundación Fungir, Amnistía Internacional, formularon informes, denuncias y acciones administrativo-jurídicas en contra de las obras. Estas reclamaron la inexistencia de consultas y consentimientos para su realización, incumplimiento de pasos previos, como el estudio de impacto ambiental y audiencias públicas. La obra se realizó, pese a las denuncias, inundando las tierras de dos comunidades Pilagá (Campo del Cielo y el Descanso) y propiedades de particulares, ubicadas próximas a la RP n. 28. Luego el Gobierno comprará voluntades a integrantes de las comunidades indígenas. La extorsión terminará avalando las obras realizadas (AMNISTÍA INTERNACIONAL, 2010, p. 46-7).

${ }^{33}$ Ver la acción de inconstitucionalidad realizado por Zapiola Luís Alberto.

${ }^{34}$ Las EAP son definidas en los CNA como la unidad de organización de la producción, con una superficie no menor a 500 m², dentro de los límites de una misma provincia que independientemente del número de parcelas (terrenos no contiguos) que la integren: Produce bienes agrícolas, pecuarios o forestales destinados al mercado. Tiene una dirección que asume la gestión y los riesgos de la actividad productiva: el productor. Utiliza los mismos medios de producción de uso durable y parte de la misma mano de obra en todas las parcelas que la integran.

${ }^{35}$ En el colectivo productor de los pequeños horticultores de Formosa, la difusión de la horticultura bajo cubierta diluyó la importancia de la espacialización horticultora desarrollada a cielo abierto por ese colectivo, así la producción formoseña comenzó a perder mercado en ese segmento. A su vez, al no tener influencia determinante en el precio del producto, ya que estos son impuestos por los intermediarios acopiadores con gran poder de negociación, fue desestimulando la actividad para el pequeño productor. Esa realidad llevó el Estado a implementar como política las ferias francas, que buscan contener a los productores y reducir la intermediación en la comercialización (ARGENTINA, 2009, p. 64). 
Cuadro 2 - Superficies implantadas de EAPs en hectáreas, por grupo de cultivos, total provincial, participación relativa y variaciones intercensales

\begin{tabular}{|c|c|c|c|c|c|c|c|c|}
\hline \multirow{2}{*}{ Grupo de Cultivos } & \multicolumn{2}{|c|}{ CNA 1988 } & \multicolumn{2}{|c|}{ CNA 2002} & $\begin{array}{c}\text { Variación } \\
\text { Intercensal } \\
\text { en \% } \\
1988-2002\end{array}$ & \multicolumn{2}{c|}{ CNA 2008 ${ }^{39}$} & $\begin{array}{c}\text { Variación } \\
\text { Intercensal } \\
\text { en \% } \\
\mathbf{2 0 0 2 - 2 0 0 8}\end{array}$ \\
\hline Total Provincial & $115.930,6$ & $100 \%$ & $119.005,4$ & $100 \%$ & $2,65 \%$ & $129.386,0$ & $100 \%$ & $24,8 \%$ \\
\hline Cereales para Grano & $17.964,1$ & $15,5 \%$ & $14.091,7$ & $11,8 \%$ & $-21,6 \%$ & $17.200,0$ & $13,3 \%$ & $22,4 \%$ \\
\hline Oleaginosas & $1.461,0$ & $1,26 \%$ & $7.888,07$ & $6,62 \%$ & $439,9 \%$ & $8.810,1$ & $6,8 \%$ & $11,7 \%$ \\
\hline Industriales & $58.537,3$ & $50,5 \%$ & $11.750,6$ & $11,2 \%$ & $-79,9 \%$ & $13.033,0$ & $10,1 \%$ & $11,8 \%$ \\
\hline Hortalizas & $8.802,0$ & $7,60 \%$ & $10.500,4$ & $8,82 \%$ & $19,3 \%$ & $4.692,5$ & $3,62 \%$ & $-55,3 \%$ \\
\hline Forrajeras & $29.166,2$ & $25,1 \%$ & $74.774,4$ & $62,8 \%$ & $156,4 \%$ & $90.342,9$ & $69,8 \%$ & $20,8 \%$ \\
\hline
\end{tabular}

Fuente: Elaboración Propia, en base a los Censos Nacionales Agropecuarios (CNA)- 1988, 2002 y 2008.

Por su parte, de la comparación de ambos CNA (2002-2008), se consolida claramente la participación significativa de la superficie implantada de forrajeras, representando casi el $70 \%$ de la superficie de EAPs en una tendencia sólida de avance de oferta alimentaria para el ganado bobino en el marco del proceso de ganaderización en la provincia Giuliano (2018, p. 239). Así, mientras en 2002 ya había un notorio crecimiento de 74.774,4 has, en 2008 subirán a 90.343 has, es decir un crecimiento de 20,8\%. Proceso que ya se manifestaba entre 1988 y 2002 como manifestación de la reestructuración productiva ganadera que irá avanzando desde el Este al Centro-Oeste de la provincia (GIULIANO, 2018, p. 240).

A esta dinámica tendencial ganadera y de agronegocios, se les sumarán las las megainversiones globales de la IIRSA ${ }^{37}$, que penetran el territorio del Centro-Oeste, encendiendo una fuerte presión sobre la disponibilidad de recursos naturales para las poblaciones originarias, cuya habitualidad y vivencia se construye en torno a la tierra y la naturaleza, lo que ha generado, nuevos escenarios de tensiones y conflicto.

En este contexto espacial disputado como observaremos, la articulación de mediaciones estatales provinciales tendrá como objetivo avanzar en la implementación de políticas productivistas fragmentarias. Así dinamiza dos líneas de política en la que busca aumentar el volumen de las explotaciones ganaderas. El primero, será el emergente de las tenciones acaecidas por las obras de la Ruta Provincial (RP) n. 28. Allí se propondrán dos planes pilotos para el afincamiento de explotaciones ganaderas con sistema silvopastoril ${ }^{38}$, llamando a los productores

\footnotetext{
${ }^{36}$ Este último ha tenido inconvenientes en su proceso de recolección de datos y en consecuencia, no se logró procesar y revelar la totalidad de la información censal, con lo cual sus datos son limitados. Sobre Formosa, solo se publicaron 17 cuadros, ubicándose entre las provincias que tuvieron una cobertura territorial entre inferior a muy inferior en relación al CNA 2002.

${ }^{37}$ La Iniciativa para la Integración de la Infraestructura Regional Suramericana (IIRSA) surgió en el año 2000 como propuesta del Banco Interamericano de Desarrollo (BID), la Corporación Andina de Fomento (CAF) y el Fondo Financiero para el Desarrollo de la Cuenca del Plata (FONPLATA) para financiar obras de inserción competitiva, eficiente en el contexto de la global, diseñados y adaptados a las cadenas agroalimentarias-ganaderas-forestoindustrial y energéticos extractivista-exportador. Formosa integra el Eje Capricornio de la IIRSA, en la que se construyen los corredores bioceánicos, se proyecta la recuperación del ramal ferroviario C 25, el tendido de la red eléctrica y el Gaseoducto del Nordeste Argentino (http://www.iirsa.org/infographic\#cap).

38 "Un sistema silvopastoril es aquel uso de la tierra y tecnologías en que leñosas perennes (árboles, arbustos, palmas y otros) son deliberadamente combinados en la misma unidad de manejo con plantas herbáceas (cultivos, pasturas) y/o animales, incluso en la misma forma de arreglo espacial o secuencia temporal, y en que hay interacciones tanto ecológicas como económicas entre los diferentes componentes" (YOUNG, 1987).
} 
a imitar, en una articulación verticalizante la experiencia extranjera menonita ${ }^{39}$ desarrollada en el territorio Paraguayo.

El segundo se encuadra en el Plan Estratégico Territorial - Formosa 2015 y dentro de ella, en el marco del Plan de Competitividad del Conglomerado Bovino. Desde esa plataforma, se avanzará en el Centro-Oeste en la conformación de más de una decena de asociaciones de pequeños productores, detrás de alcanzar el desarrollo de sus localidades.

En una tercera línea de políticas fragmentarias, pero que a su vez se alineará al consenso de los grupos ganaderos, se vectoriza el re-escalamiento hacia abajo en la localidad de Ingeniero Juárez, en articulación con Agencias globales como la Red Regional de Bosques Modelos para América Latina y El Caribe (CRBM-LAC) y la Agencia Internacional de Cooperación Japonesa-JICA generando la implementación del plan estratégico Bosque Modelo Formoseño (BMF).
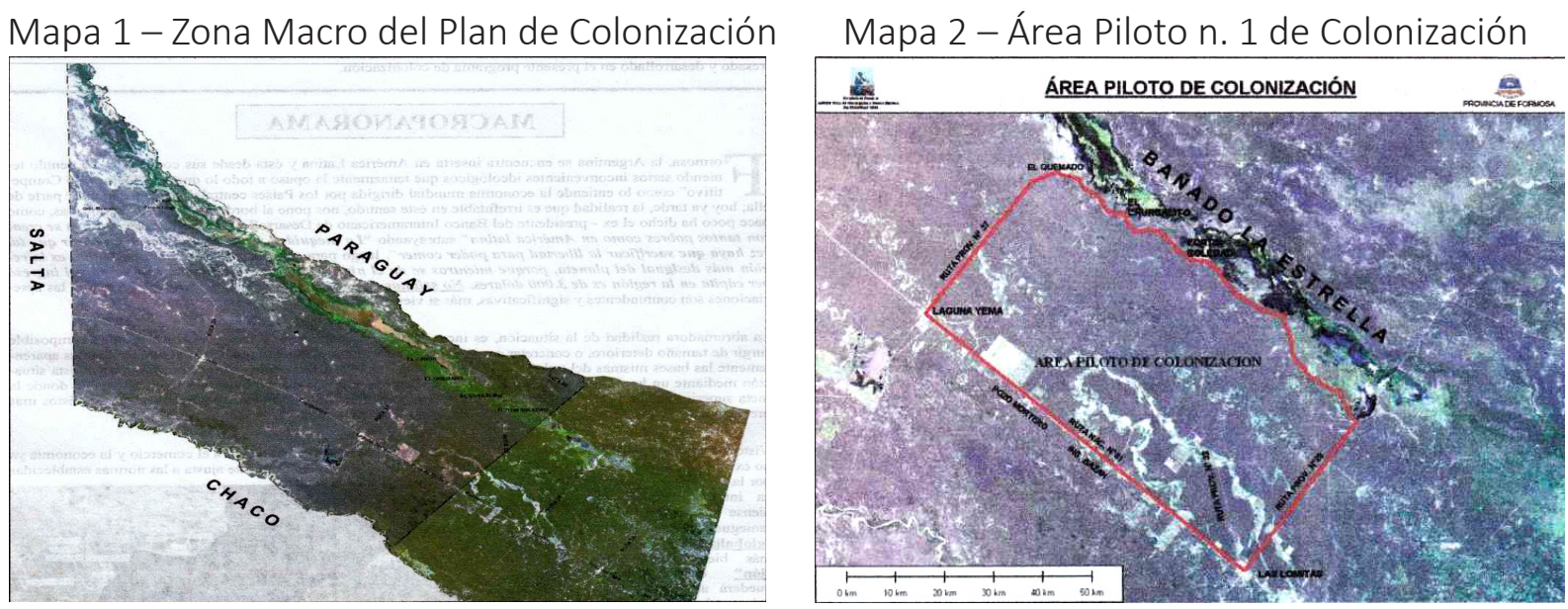

Fuente: Instituto de Colonización y Tierras Fiscales. Plan de Colonización y Ordenamiento Territorial y Catastral de la tierra Pública, p. 11 y 37.

En efecto, en el año 2006, el Instituto Provincial de Colonización y Tierras Fiscales redacta el plan piloto aludido, con dos áreas de colonización, siendo estas, los ejes vertebrales del Programa Integral de Colonización y Ordenamiento Territorial y Catastral de la tierra Pública en el Oeste formoseño (PICOTyCPO). Si bien este último, contempla el tratamiento técnico en una zona macro de unas 2,2 millones de hectáreas, comprendida desde la Ruta Provincial n. 24 hasta la Línea Barilari, como se observa en el Mapa n. 1; el área piloto n. 1 de Colonización-ver Mapa 2-, se ubica adyacente al territorio afectado por las obras de la Ruta Provincia n. 28.

Esta área piloto, de unas 175 mil hectáreas estimadas. Define sus límites entre la Ruta provincial n. 28 al Este, al Norte el límite Sur del Bañado La Estrella, la Ruta provincial n. 37 al Oeste y la Ruta Nacional n. 81 al sur; todo ello al Norte de los Pueblos de Pozo Mortero y Las Lomitas. Incluye a unos 200 productores homogéneos ${ }^{40}$, según las perspectivas del plan.

\footnotetext{
${ }^{39}$ La experiencia que se plantea imitar en el plan formoseño, es el de la Colonia Menonita de Fernheim, conocida como Filadelfia, en la República del Paraguay.

${ }^{40}$ Se tratan de 200 explotaciones ganaderas, sin ninguna diferenciación entre ellas. Por el contrario, se avanza en las estimaciones de implantes de pasturas y cría de ganado bovino en proyección lineal (INSTITUTO PROVINCIAL DE COLONIZACIÓN Y TIERRAS FISCALES, PROVINCIA DE FORMOSA, 2006, p. 38-9).
} 
En tanto que el área piloto n. 2, abarca una superficie de unas 26.167 hectáreas, inclusiva de unos 26 productores $^{41}$, en la zona de La Diosa y San Marcos, anexa también, al territorio del conflicto aludido. Ubicándose dentro del área de la Sección 9na y la Colonia Juan Bautista Alberdi al Este y Oeste de la Ruta Provincial n. 28.

En términos generales el PICOTYCPO, será presentado a los productores del Bañado la Estrella, como la fuente cierta de ingresos sustentables, crecimiento y desarrollo; para lo cual se los convoca a seguir las experiencias convalidadas en la colonia menonita paraguaya Filadelfia. Para ello, se apela a la validación empírica exitosa a imitar a través de imágenes satelitales de la colonia y también de empresas extra-provinciales instaladas en el Centro-Oeste, que utilizan el mismo sistema. En el plan se esgrime al respecto:

[...] El área Filadelfia, a unos $150 \mathrm{~km}$ al norte del límite internacional República Argentina Paraguay a la altura de Las Lomitas. Zona conocida como Colonia menonita. Han desmontado una superficie total de 2.500.000 hectáreas, donde mantienen unas 3.000.000 de cabezas de ganado vacuno, todo ello en un lapso de 30 años con lo que queda demostrado sobradamente la sustentabilidad de la técnica empleada, que justamente es similar a la que se propone implementar en el presente Proyecto de Colonización. [...] Si ellos lo han hecho, es posible reproducir el mismo modelo en la zona Oeste de nuestra Provincia. (INSTITUTO PROVINCIAL DE COLONIZACIÓN Y TIERRAS FISCALES, 2006, p. 13).

Por su parte, el área piloto n. 2 se dinamiza el 6 de enero de 2006 en el paraje La Diosa. Allí el PEP autoriza y delinea la conformación de una Asociación de Productores bajo la promesa de mejores oportunidades y atendidos por un modelo productivo ganadero que generará por sí solo, ingresos para los productores y el ansiado desarrollo para el Oeste formoseño. Al respecto se afirmará:

[...] El modelo productivo ganadero con el sistema silvo-pastoril, es el ideal para seguir desarrollando al Oeste formoseño. Su entendimiento es sencillo, todo se basa en implementar pasturas artificiales, mejor manejo de la hacienda y perfección de su genética, las demás necesidades (apotreramiento, corrales, baño, balanza, etc.) se irán concretando de por sí en el entendimiento de que la propia necesidad de los productores más el incremento notable de sus ingresos los habilitará para implementarlos. (INSTITUTO PROVINCIAL DE COLONIZACIÓN Y TIERRAS FISCALES, 2006, p. 16).

Bajo estos principios que entienden al desarrollo a partir de la dinámica de las fuerzas locales, el mejoramiento de la competitividad para la inserción global, en 2010 se planteará en el Plan de Competitividad del Conglomerado Bovino (PCCB) una segunda línea de trabajo, consistente en la conformación de más de una decena de asociaciones de pequeños productores detrás de conseguir el anhelado desarrollo en aquel territorio.

Este plan, se había gestado entre la Comisión Interna de la Sociedad Rural de Formosa Ilamada Cabañas Formoseñas y el Ministerio de la Producción y en línea con el Plan Estratégico Territorial de Formosa 2015. Aquí, a diferencia de la experiencia del PICOTyCPO, el documento del PCCB se mostrará como un producto consensuado y participativo, en la que se definen ejes estratégicos, líneas de acción e ideas de proyectos de apoyo a la competitividad ${ }^{42}$. En este sentido el plan proyecta como idea que:

\footnotetext{
${ }^{41}$ El programa abarcaba a 26 productores, identificados y estratificados según la superficie de tierra ocupada y estado legal, es decir, que entre ellos hay productores con Adjudicaciones en Venta, Propiedad Particular, Permisos de Ocupación y fiscales. (INSTITUTO PROVINCIAL DE COLONIZACIÓN Y TIERRAS FISCALES, 2006, p. 42).

42 Para mayores detalles sobre los ejes estratégicos, líneas de acción e ideas de proyectos ver en Ministerio de Economía y Finanzas Públicas de la Nación (2010, p. 39-52).
} 
[...] Con la formación de grupos asociativos de productores, se logrará adquirir maquinaria que de otra forma sería dificultoso, por la magnitud de la inversión necesaria. Con esto se logrará realizar actividades tales como siembra y confección de reservas forrajeras [...]. Para el pequeño productor esta idea proyecto constituye la posibilidad de agregarle valor a su producción, tanto en una mejora de la calidad como así también en un aumento de los kilos de carne producidos. Para ello se contempla el armado de un campo con implantación de pasturas y apotreramiento adecuado ejecutado por una asociación de productores y asistido técnicamente por asesores del Plan Ganadero Provincial. (MINISTERIO DE ECONOMÍA Y FINANZAS PÚBLICAS DE LA NACIÓN, 2010, p. 40-2).

De este modo, se reforzaba el direccionamiento y el liderazgo fijado por los intereses ganaderos dominantes, que entienden al sistema primario y su cambio eficiente a partir de la consolidación y avance sus fracciones de intereses en el territorio, con el objetivo de convertir a la región en praderas con implantaciones de pasturas, reservas forrajeras y asistencia técnica que facilite la atmosfera propicia para mediaciones con los pequeños productores.

En la Municipalidad de Ingeniero Juárez ${ }^{43}$, en tanto, se articularán con las Agencias Globales ${ }^{44}$ la implementación del plan estratégico BMF, de base conceptual canadiense y extendida a escala mundial. Su esquema de funcionamiento que integra distintas instituciones ${ }^{45}$, no cuenta con financiamiento propio, recibe para ello asistencia financiera de las Agencias Globales ${ }^{46}$ focalizadas en proyectos liderados por estas últimas.

Se trata entonces, de una herramienta de estilo bottom-up, referente del Plan Estratégico de desarrollo Local de Ingeniero Juárez (BOSQUE MODELO, 2009, p. 12), concordante a las ideas de la NOR, cuya implicancia sub-nacional se acopla a la dinámica consensuadas hacia arriba, con las Agencias Globales aludidas, su financiamiento y directrices. Hacia abajo, con las instituciones estaduales provinciales y su apoyo financiero, a cambio de colaborar en la construcción de nuevos actores que se alineen a los intereses ganaderos dominantes y la organización de los primeros remates ${ }^{47}$. Al respecto se expresa:

[...] El Bosque Modelo [...] Colabora con la formación de nuevas asociaciones y participa de charlas para trabajar con estas. Es así que ha trabajado junto a productores en la Formación de la Federación de Productores del Extremo Oeste (FAPEO) que vincula diez (10) asociaciones de productores pecuarios con 250 socios en total. Estos son productores pecuarios del departamento de Matacos y Ramón Lista, y como logro tiene la organización del primer remate de hacienda de la zona mejorando de manera notable la rentabilidad de sus socios. (BOSQUE MODELO, 2010, p. 10).

El plan BMF, ha incidido además en la elaboración de los corredores de áreas de conservación de parques protegidos, la zonificación y expansión de la superficie potencialmente explotable definido en el Plan de Ordenamiento territorial de Formosa (POT - For) ${ }^{48}$ a partir de

\footnotetext{
${ }^{43}$ Localidad ubicada en el Oeste de la Provincia de Formosa en el Departamento Matacos.

${ }^{44}$ Entre ellas la Red Regional de Bosques Modelos para América Latina y El Caribe (CRBM-LAC), la Agencia Internacional de Cooperación Japonesa-JICA, y el Programa Fondos Semillas de la Red Iberoamericana de Bosque Modelo.

${ }^{45}$ Entre estas instituciones encontramos a: 1) Gubernamentales: Municipalidad de Ingeniero Juárez (cuyo Intendente preside el BMF), Ministerio de la Producción y Ambiente, CEDEVA, INTA, Unaf, Administración de Parques Nacionales Reserva Natural Formosa, Instituto PAIPPA, Oficina de Empleo de Ingeniero Juárez, Servicio Nacional de Sanidad y Calidad AgroalimentariaSENASA; 2) No Gubernamentales: Asociación de Madereros, Federación de Asociaciones de Productores del Extremo Oeste, Comunidad Toba Com' Lec, Comunidad Wichí La Esperanza, Comunidad Wichí El Mistolar, EPRASOL.

${ }^{46}$ Véase al respecto el trabajo de Ernesto Fabián Giuliano (2018, p. 259).

${ }^{47}$ Diario El Comercial, Miércoles, 8 de agosto de 2012.

${ }^{48}$ ADÁMOLI, GINZBURG Y TORELLA (2009) identifican tres zonas: 1) La occidental, 2) Los corredores de conservación y 3) La
} 
la obligatoriedad de la Ley Nacional n. 26.331 (BOSQUE MODELO, 2010, p. 9).

Así entonces, mientras las estrategias que llegan al BMF desde la escala global, nacional o provincial se orientan a generar arreglos escalares verticalizantes de consenso con los capitales ganaderos y sus explotaciones; los directos beneficiarios del BMF (pueblos originarios y pequeños productores) son contenidos con fondos que llegan como donaciones para desarrollar proyectos en el territorio, con escasa autonomía para su gestión y muchas veces incongruentes con las necesidades sus beneficiarios:

[...] Los cambios a realizarse deberán enfocarse en lograr mejores ajustes de los proyectos en los beneficiarios en post de que los donantes cedan o depositen confianza en los ejecutores. Hemos tenido dificultades y consideramos que responden al diseño de los proyectos que se ajustan más a las necesidades del donante de controlar y monitorear los proyectos, que a la de los beneficiarios, y a la hora de la ejecución notamos serias dificultades para la apropiación del proyecto. (BOSQUE MODELO, 2009, p. 13).

Simultáneamente a estos procesos de territorialización fragmentaria y de gran presión sobre los recursos naturales, las mediaciones estatales se vuelcan ampliar la penetración de los grupos de empresas ganaderas y agrícolas que a mediados de los años 1990, ya comenzaban a afincarse en las márgenes del Canal de agua Laguna Yema - Las Lomitas. Esas mediaciones buscan mostrar como casos exitosos a imitar, a las empresas que en el marco del PICOTyCPO utilizan el sistema silvo-pastoril promovido en dicho plan. Así también, se señala el éxito de las empresas agrícolas que avanzan en las exportaciones de sus productos.

Al respecto en el año 2006, se muestra la inserción de las empresas Garlisi Cereales S.A. de los hermanos Gómez Luna ${ }^{49}$, de la provincia del Chaco (INSTITUTO PROVINCIAL DE COLONIZACIÓN Y TIERRAS FISCALES, 2006, p. 31) a pocos kilómetros de Las Lomitas; la cabaña del empresario ganadero Juan Rolando Bunchich que comprará 2.000 hectáreas de tierra (INSTITUTO PROVINCIAL DE COLONIZACIÓN Y TIERRAS FISCALES, 2006, p. 29). Luego, la firma PROAGRO ${ }^{50}$ S.A. (INSTITUTO PROVINCIAL DE COLONIZACIÓN Y TIERRAS FISCALES, 2006, p. 33) y la empresa ICBERG S.A $A^{51}$. En tanto que a la firma Sumayen S.A., se la mostrará en medios de información nacional, como desarrolladora de cultivos pocos tradicionales en la región, como los espárragos con destino exportable a la Unión Europea ${ }^{52}$.

En el 2007, y después de un año de negociaciones con L.I.A.G. S.A, el gobierno provincial decidirá quitar a la firma 30.634 hectáreas, por incumplimientos en las inversiones previstas en el proyecto $^{53}$. No obstante esta decisión, la empresa continúa operando en la actualidad en la localidad de Laguna Yema, con una extensión de 9.366 hectáreas de las cuales más de 5.000 operan bajo riego.

oriental. Las tres habilitan nuevas superficies de tierras, potencialmente explotable, alcanzando a unas 2,6 millones de hectáreas que, sumados a las explotaciones actuales y por realizarse, llegan a más de 3 millones de hectáreas.

${ }^{49}$ Son 15.000 hectáreas en el área de colonización Las Lomitas-Bazán, con destino a la agricultura y la ganadería bovina a través de prácticas silvo-pastoril.

${ }^{50}$ El grupo empresario lo integran, los hermanos Cavigliaso de Río Cuarto, Córdoba, Carlos Kerdinesnky, de Formosa y la firma Winter Hermanos. De 8.000 hectáreas, destinan 2.000 a la producción de maní tipo confitería, exportables a la Unión Europea, Japón y China (Infocampo.com.ar).

${ }^{51}$ Se trata de una de uno de los actores importantes del rubro de la horticultura, dedicado a la producción de zapallos anco con destinos exportables a Inglaterra, Holanda y Alemania.

52 Diario La Nación, 17 de septiembre de 2005.

${ }^{53}$ Se trató de una decisión negociada, dado el incumplimiento cabal del proyecto original, que preveía una inversión de 52 millones de dólares y la puesta en producción de 18.000 hectáreas, más la instalación de una desmotadora de Algodón. (Diario La Nación, 31 de diciembre de 2007). 


\section{REFLEXIONES FINALES}

Se ha podido observar que el patrón regulativo escalar de la fase neoliberal que se consolidó en los años 1990, a través de las reformas estructurales y la retracción del Estado, luego se combina con el roll out para vehiculizar la continuidad y la reelaboración del proceso neoliberal a través de la plataforma única localista o NOR. La región espacial del Centro-Oeste de Formosa muestra concretamente el despliegue de esta intervención. En esa dinámica, el acoplamiento de las políticas públicas en el anclaje estudiado, revelan la puesta en juego de un conjunto dispositivos regulativos fragmentarios y de estrategias de actores diversos, que van caracterizando al espacio de acumulación con elementos que marcan la selectividad de las políticas públicas, las tensiones y disputas por los recursos naturales.

Esa dinámica procesual, al trabajar institucionalizadas a través de políticas desarticuladoras y fragmentarias, genera un profundo proceso de re-escalamiento del Estado y de territorialización que se acoplan y dinamizan la reproducción neoliberal y sus nuevas formas de mercantilización y subordinación. De allí, que resulta imprescindible en contextos periféricos como los de Formosa, conocer cómo opera dicho proceso, ya que, al estar ausente del aparato discursivo de la plataforma única localista, cuál es el papel que juegan las escalas. En consecuencia, no existe en dicha plataforma común, una centralidad puesta sobre el papel del Estado.

Ello es producto del patrón regulativo escalar y de infraestructuras que de manera fragmentaria, como observamos, cuando se dinamiza institucionaliza en el espacio, se funcionaliza a través de complejos procesos mediados por los policymakers con las fracciones del capital ganadero, de los agronegocios y de organizaciones globales que penetran y presionan a los actores más vulnerables, como las poblaciones originarias o los pequeños productores, quedando estos como sujetos de una promesa embebida en lograr el desarrollo y un mejor bienestar, según presagian los postulados de la NOR.

Sin embargo, su despliegue incorporado en el territorio, como se ha observado, genera relaciones jerárquicas de tamaño, poder y decisiones sobre los recursos naturales que resultan ser asimétricos e inestables desde los social, económico y político. De modo que el espacio se transforma, pero de manera desigual.

\section{REFERENCIAS}

ADÁMOLI, J.; GINZBURG, R.; TORELLA, S. POT-For, 2009. Disponible en: http://www.elcomercial.com.ar/ descargas/POTley.pdf. 2009, p. 15. Acceso el: 3 feb. 2011.

AMNISTÍA INTERNACIONAL. Exigimos respeto - Argentina: los derechos de los Pilagás del Bañado la Estrella. Buenos Aires, Argentina: Amnistía Internacional, 2010. Disponible en: https://www.amnesty. org/download/Documents/36000/amr130012010es.pdf. Acceso el: 20 jul. 2012.

AMIN, Ash. Una Perspectiva Institucionalista sobre el desarrollo Regional. Ekonomiaz- Revista Vasca de Economía, n. 41, p. 68-89, 1998. Disponible en: http://dialnet.unirioja.es/ejemplar/56237. 1998. Acceso el: 10 jun. 2010.

AZCUY AMEGHINO, Eduardo; ORTEGA, Lucía E. Sojización y expansión de la frontera agropecuaria en el NEA y el NOA: transformaciones, problemas y debates. Centro Interdisciplinario de Estudios Agrarios de la Universidad de Buenos Aires. Documento del CIEA n. 5, 2016. Disponible en: http://www.ciea.com.ar/ web/wp-content/uploads/2016/11/Doc5_7.pdf 2016. Acceso el: 7 nov. 2016. 
BECATTINI, Giacomo. El Distrito Marshalliano: una noción Socioeconómica. En: Las Regiones que Ganan: Distritos y Redes. Los nuevos paradigmas de la geografía económica. Valencia. España: Alfonso el Magnánimo,1992. p. 39-57.

BENKO, George; LIPIETZ, Alain. De la regulación de los espacios a los espacios de la regulación. Diseño y Sociedad, México, n. 5, 1995.

BOSQUE MODELO. Anuario 2009: Bosques Modelo de iberoamérica. Costa Rica: RIABM, 2009. Disponible en: http://www.bosquesmodelo.net/spanish/herramientas/content/documentos/AnuarioBM2009_ RIABM.pdf. Acceso el: 20 enero 2010.

BOSQUE MODELO. Anuario 2010: Bosques Modelo de iberoamérica. Costa Rica: RIABM,. 2010. Disponible en: http://www.bosquesmodelo.net/archivo-publicaciones/De_la_RIABM/Anuarios/Anuario2010_RIABM. pdf 2010. Acceso el 3 mayo 2014.

BOBADILLA DE GANE, V; SILVA, Rafael A. Formosa recursos, ambiente y posibilidades para el desarrollo. El Docente. Formosa, Argentina, 2004. p. 138-44.

BRANDÃO, Carlos A. Território y desenvolvimento: as múltiplas escalas entre o local e o global. Campinas, SP: Editoria Unicamp, 2007.

BRENNER, Neil. Glocalization as a state spatial strategy: urban entrepeneurialism and the new politics of uneven development in western Europe. En: PECK, Jamie; WAI-CHUNGYEUNG, Henry (Ed.). Remaking the global economy: economic-geographical perspectives. London: Sage, 2003. p. 197-215.

BRENNER, Neil; PECK, Jamie; THEODORE, Nik. After neoliberalization? Globalizations, v. 7, n. 3, p. 327-45, 2010.

BROWN, Alejandro D.; FOGUET, María José; MORITÁN, Matilde García; MALIZIA, Sebastián. Bitácora del Bañado la Estrella: dinámica fluvial de un espacio compartido. Salta: Artes Gráficas Crivelli, 2010. Disponible en: http://proyungas.org.ar/wp-content/uploads/2015/05/Bitacora-Ba\%C3\%B1ado-la-Estrella. pdf. Acceso el: 2 enero 2012.

COOKE, Philip. Regional Innovation Systems: competitive regulation in the New Europe. Geoforum, n. 23, p. 365-82, 1992.

DIARIO EL COMERCIAL, Formosa, Argentina, 12 septiembre 2008. Disponible en: http://elcomercial.com. ar/archivo-online/2008/SEPTIEMBRE/12-09-08/index.asp. Acceso el: 12 sept. 2008.

DIARIO EL COMERCIAL. Formosa, Argentina, 8 agosto 2012. Disponible en: http://www.elcomercial.com.ar/ index.php?option=com_content $\&$ view=article\&id=84385: exitoso-tercer-remate-ganadero-en-ingenierojuarez\&catid $=54 \&$ Itemid=55. Acceso el: 8 agosto 2012.

DIARIO LA NACIÓN. Economía, Campo. Buenos Aires, Argentina, 17 septiembre, 2005. Disponible en: http://www.lanacion.com.ar/739334-la-ventaja-de-cosechar-antes-que-todos. Acceso el: 17 sept. 2005.

DIARIO LA NACIÓN, Economía, Buenos Aires, Argentina, 31 diciembre 2007. Disponible en: http://www. lanacion.com.ar/975287-marcha-atras-en-una-venta-de-tierras-fiscales-en-formosa. Acceso el: 31 dic. 2007.

FERNÁNDEZ, Víctor R.; AMIN, Ash; VIGIL, José I. Repensando el Desarrollo Regional: contribuciones globales para una estrategia latinoamericana. Buenos Aires: Miño y Dávila, Argentina, 2008.

FERNÁNDEZ, Víctor R.; GARCÍA PUENTE, María J. Transformaciones Estatales ¿Cambio en sus funciones? Revisando perspectivas teóricas para analizar el Estado contemporáneo. Revista de la Facultad de Ciencias Jurídicas y Sociales, v. 1, n. 8, p. 137-48, 2010. 
FERNÁNDEZ, Víctor R.; VIGIL, José I.; SEVAL Martín. Explorando la Región: territorios, escalas y relacionalidades. Revista de Geografía Norte Grande, 51, p. 21-41, 2012.

GIULIANO, Ernesto Fabián. Sociedades Periféricas y Multiterritorios: análisis de la estructura social de Formosa en el ciclo 1980-2002., Buenos Aires, Argentina: La Colmena, 2015.

GIULIANO, Ernesto Fabián. Los cambios a nivel funcional y espacial del Estado y la Estructura territorial productiva formoseña. Análisis del ciclo 1991-2012. 2018. Tesis (Doctoral en Ciencias Sociales)- Universidad de Buenos Aires, Buenos Aires, Argentina, 2018.

HARVEY, David. El nuevo imperialismo: acumulación por desposesión. En: PANITCH, Leo; LEYS, Colin. Socialist Register: el nuevo desafío imperial. Buenos Aires, Clacso, 2004. p. 99-129.

INSTITUTO PROVINCIAL DE COLONIZACIÓN Y TIERRAS FISCALES. Plan de colonización y ordenamiento territorial y catastral de la tierra pública. Plan de afincamiento de explotaciones ganaderas sistema silvopastoril con presupuesto. Provincia de Formosa, 2006. Disponible en: http://www.pilcomayo.net/media/ biblioteca/libro_1070_SE-094.pdf.2006. Acceso el: 11 oct. 2008.

MANÍ: se afirma la producción en Formosa. Infocampo.com.ar, 3 noviembre 2006. Disponible en: http:// infocampo.com.ar/nota/campo/8532/mani-se-afirma-la-produccion-en-formosa. Acceso el: 11 feb. 2007.

JESSOP, Robert. El futuro del Estado Capitalista. Madrid: De la Catarata, 2008.

MINISTERIO DE ECONOMÍA Y FINANZAS PÚBLICAS DE LA NACIÓN. Plan de competitividad del Norte Grande. Plan de Competitividad del Conglomerado Ganadero Bovino de Formosa. Formosa, 2010. Disponible en: https://www.economia.gob.ar/programanortegrande/docs/Plan\%20de\%20Competitividad\%20Bovino\%20 -\%20Formosa.pdf. Acceso el: 12 oct. 2011.

MINISTERIO DEL INTERIOR DE LA NACIÓN. Plan Estratégico Territorial Formosa 2015: El plan de inversiones que conduce a la visión de largo plazo. Formosa, 2015. Disponible en: https://www.mininterior.gob.ar/ planificacion/pdf/planes-prov/FORMOSA/Plan-Estrategico-Formosa-2015.pdf. Acceso el: 2 jun. 2010.

MINISTERIO DE LA PRODUCCIÓN. Provincia de Formosa. Disponible en: https://www.formosa.gob.ar/ produccion/programas/desarrollointegral. Acceso el: 11 oct. 2018.

LIPIETZ, Alain. El posfordismo y sus espacios. Series Seminarios de Investigación Intensivos. Documento de Trabajo n. 4, PIETTE-CONICET, Facultad de Ciencias Económicas de la Universidad de Buenos Aires, Buenos Aires, 1994. p. 1-52.

PECK, Jamie. Economías y políticas de escala: políticas rápidas, relaciones inter escalares y workfare neoliberal. En: FERNÁNDEZ, V.; BRANDÃO, C. (Org.). Escalas y Políticas del desarrollo regional: desafíos para América Latina. Buenos Aires: Miño \& Dávila, 2010. p. 77-120

PECK, Jamie; TICKELL, Adam. Searching for a new institucional fix: the after-fordist crisis and the globallocal disorder. En: AMIN, Ash (Ed.). Post-Fordism: a reader. Malden, Mass: Blackwell, 1994. p. 280-315.

PECK, Jamie; TICKELL, Adam. Making global rules. Globalization or neoliberalization? En: PECK, Jamie; YOUNG, Henry Wai-chung (Ed.). Making the global economy. London: Sage, 2003. p. 163-81.

PECK, Jamie; TICKELL, Adam. Conceptualizing neoliberalism, thinking Thatcherism. En: LEITNER, Helga; PECK, Jamie; SHEPPARD, Eric (Ed.). Contesting neoliberalism: urban frontiers. New York: The Guilford Press, 2007. p. 26-50.

PORTER, Michael. Clusters and the new economics of competition. Harvard Business Review. Reprint number - nov./dic. 1998. Disponible en: http://www.rimisp.org/wp-content/uploads/2012/07/31_rimisp_ 
Cardumen.pdf. Acceso el: 31 jul. 2012.

ARGENTINA. Ministerio de Agricultura Ganadería y Pesca de la Nación. Estrategia Provincial Para El Sector Agroalimentario (EPSA). Programa de Servicios Agrícolas Provinciales (PROSAP), Buenos Aires, 2009. p. 1-97.

ROFMAN, A. y ROMERO, L. Sistema Socioeconómico y Estructura Regional en la Argentina., Buenos Aires, Argentina: Amorrortu, 1997.

SUED, Gabriel. Los secretos de Gildo Insfrán, el modelo de gobernante perpetuó. Buenos Aires, Argentina: Diario La Nación, 2006. Disponible en: https://www.lanación.com.ar/política/los-secretros-de-gildoinsfran-el-modelo-de-gobernante-perpetuo-nid864570. Acceso el: 4 dic. 2006.

SWYNGEDOUW, Erik. ¿Globalización o glocalización? Redes, territorios y reescalonamiento. Universidad de Manchester. Capítulo 1. En: FERNÁNDEZ, V. R.; BRANDÃO, C. Escalas y políticas del desarrollo regional: desafíos para América Latina. Buenos Aires, Argentina: Miño y Dávila, 2010.

VACA, J.; CAO, H. La división regional del trabajo en la Argentina: nuevos elementos y tradicionales desequilibrios, Realidad Económica, n. 202, p. 65-86, 2004.

ZAPIOLA, Luis M. Acción de Insconstitucionalidad- Ley 1471. Redaf, 29 agosto, 2007. Disponible en: http:// redaf.org.ar/accion-de-inconstitucionalidad-ley-1471/. Acceso el: 11 feb. 2018.

\section{Sobre el autor:}

Ernesto Fabián Giuliano: Doctor en Ciencias Sociales, Universidad de Buenos Aries, Buenos Aires, Argentina. Magister en Gestión Territorial y Desarrollo, Universidad Nacional de Rosario, Santa Fe, Argentina. Economista, Universidad Nacional de Córdoba, Córdoba, Argentina. Docente e investigador de la Facultad de Administración, Economía y Negocios (Faen) de la Universidad Nacional de Formosa (UnaF). Línea de investigación: Desarrollo Regional, Estudios Estatales, Estudios Socioterritoriales.

E-mail: giulianoernesto02@gmail.com. Orcid: http://orcid.org/0000-0002-9699-8148 